\title{
A modified repair for the anterior cruciate ligament deficient knee
}

\author{
James P. Holland FRCS \\ Birmingham Accident Hospital, Birmingham, UK
}

\begin{abstract}
A retrospective analysis of $\mathbf{4 8}$ sportsmen and women from an original series of 76 consecutive patients who had undergone a modified McIntosh repair was carried out to establish whether or not the procedure could provide a satisfactory recovery and return to previous ability. The type and level of sport before injury was compared with that after operation. Symptoms of pain and giving way, and examination findings of pivot shift, and Lachman's test were compared before and after operation. Of the 48 patients assessed, $28(58 \%)$ returned to full sporting capacity; $17(35 \%)$ patients were participating in different sports or lower levels of their previous sports, and three patients did not participate in any sport. The more severely symptomatic knees did not perform so well after operation. The degree of preoperative anterior draw and Lachman's test did not influence the final result and the pivot shift, present in all before operation, was abolished in all but one case, which remained badly symptomatic. Concurrent meniscal injury or medial or lateral laxity did not influence return to sport once a full postoperative recovery was made. No deterioration was noticed in the level of sporting ability achieved thereafter. In this study it has been shown that the modified McIntosh repair is a swift extra-articular reconstruction for the anterior cruciate ligament deficient knee, which is less elaborate than previously described Ellison and McIntosh procedures, and which has produced a comparable result.
\end{abstract}

Keywords: Anterior cruciate ligament, pivot shift test, Lachman's test, McIntosh repair, sporting outcome

Deficiency of the anterior cruciate ligament (ACL), a primary stabilizer of the tibia on the femur, has been well documented as a cause of anterolateral rotatory instability and subsequent loss of knee function. Correction has been attempted in numerous ways. Intra-articular tendon reconstruction has been employed with some success by Jones ${ }^{1}$, using the patellar tendon and $\mathrm{O}^{\prime}$ Donoghue ${ }^{2}$ using iliotibial tract. Gracilis ${ }^{3}$ and semitendinosus ${ }^{4}$ tendon transfers have also been used. Intra-articular prosthetic ACL replacement using Gore-Tex polytetrafluoroethylene (PTFE) has produced variable results due to a loosening of the graft and resorption of interposed soft tissue. Its use in sportsmen is not recommended;

Address for correspondence: Mr J. P. Holland FRCS, Registrar, Birmingham Accident Hospital, Bath Row, Birmingham B15 1NA, UK

(C) 1992 Butterworth-Heinemann Ltd 0306-3674/92/040249-04 however it has a place in the treatment of previous operative failures or in older, less active patients ${ }^{5}$.

Extra-articular transfer of a powerful iliotibial band taken from iliotibial tract, however, has been shown to have consistently good results ${ }^{6}$. Ellison's technique is to detach the iliotibial band distally along with the bone of Gerdy's tubercle, re-routing under the fibular collateral ligament before re-insertion by stapling.

McIntosh and Darby ${ }^{7}$ describe a similar procedure detaching a strip of iliotibial tract proximally, re-routing beneath the fibular collateral ligament and a fibro-osseus tunnel in the posterolateral femoral condyle before suturing to the lateral intermuscular septum. Results have been similar to the Ellison procedure.

The modified McIntosh repair is an extra-articular reconstruction which takes approximately $20 \mathrm{~min}$ to perform, with plaster time in addition.

\section{Materials and methods}

Of 76 consecutive patients undergoing the modified McIntosh repair between July 1984 and December 1988 by the same surgeon, 48 were available for retrospective analysis. At review, details of pre-injury sporting activity, symptoms and signs before operation including 'giving way', Lachman displacement and pivot shift were noted by the operating surgeon. It was also noted whether the patient had concurrently undergone meniscal surgery at the time of reconstruction.

'Giving way' was graded as occurring at any time, regularly at sport, occasionally at sport, feeling unstable only or nil. Lachman displacement was measured in millimetres and was found to be more accurately reproducible between the original operator and trial examiner than anterior draw. Pivot shift was classed as present or absent, under general anaesthesia at operation.

At the review clinic details of present level and type of sport were obtained. Subjective symptoms of giving way were graded before operation, as well as pain. Each patient was again examined for Lachman displacement and pivot shift.

\section{Operation}

Each operation was performed by the same surgeon taking approximately $20 \mathrm{~min}$, with plaster time in addition. 
Through a $20-\mathrm{cm}$ lateral knee incision, the iliotibial tract is exposed down to its insertion into Gerdy's tubercle. A longitudinal strip $20 \mathrm{~cm} \times 2 \mathrm{~cm}$ is cut from the tract based on Gerdy's tubercle and detached proximally. This is re-routed deep to the lateral ligament and the thickened band of the lateral intermuscular septum. It is then sutured back to its origin. The skin is closed and the leg enclosed in plaster-of-Paris in $20^{\circ}$ of knee flexion and in full external rotation for 6 weeks. Intensive outpatient physiotherapy is started after removal of the plaster.

\section{Results}

The 76 patients (all active sportsmen and women before injury which required operative intervention), underwent the modified McIntosh repair between July 1984 and December 1988. Of these patients, 48 (38 men and 10 women) were available for review. Follow-up varied from 12 months to 60 months, mode 12 months and mean 26 months.

At review, 28 patients $(58 \%)$ were performing at the same level of the same sport as before operation, 17 patients $(35 \%)$ had returned to a lower level of previous sport or a different sport, and three patients (6\%) did not participate in any sport. These three groups are represented in relation to period of follow-up in Figure 1.

Before operation, the predominant symptom of all patients was giving way. This was present in varying degrees as shown in Table 1, with corresponding inability to perform in sport and in some cases affected work and general lifestyle. These symptoms are grouped together with postoperative outcome and show a preponderance of milder preoperative symptoms in the group returning to the same sport, a more even spread in those returning to less sport and more severe symptoms in those not returning to sport.

Table 2 shows the 'giving way' felt by patients after operation. For the group as a whole, 31 (65\%) had experienced none since operation but only 18 of these had returned to full sporting status. Only seven

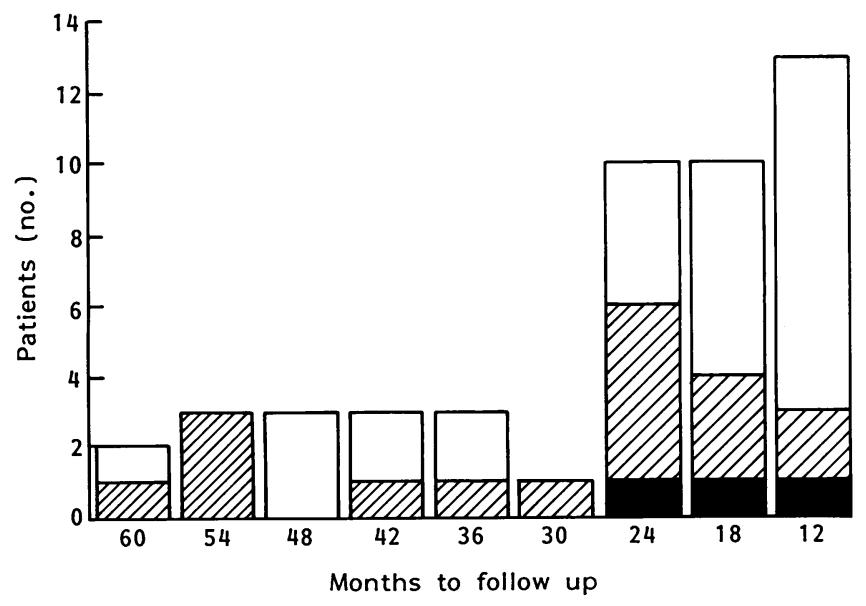

Figure 1. Sporting outcome in 48 patients undergoing a modified Mclntosh procedure, $\square$, same sport; $\square$, less sport; $\square$, no sport patients $(15 \%)$ had experienced giving way after operation (five occasionally and two regularly), three of these had returned to full sporting activity.

Lachman displacement was assessed by the operating surgeon before operation (Table 3), and by one examiner in the review clinic (Table 4). By comparing these two tables, again grouped for postoperative outcome, the improvement to 'nil displacement' in 20 cases can be seen. It is also evident from Table 3 that the distribution of degree of Lachman displacement is similar in all three outcome groups. This would indicate that degree of displacement before operation is not relevant to outcome in terms of return to sport.

Pivot shift, which was present in all patients before operation, could only be elicited in one patient after operation.

Table 1. Subjective degree of 'giving way' before operation

\begin{tabular}{|c|c|c|c|c|c|c|}
\hline $\begin{array}{l}\text { Result } \\
\text { after } \\
\text { operation }\end{array}$ & Nil & $\begin{array}{c}\text { Felt } \\
\text { unstable }\end{array}$ & $\begin{array}{l}\text { Occasionally } \\
\text { at sport }\end{array}$ & $\begin{array}{l}\text { Regularly } \\
\text { at sport }\end{array}$ & $\begin{array}{l}\text { Any } \\
\text { time }\end{array}$ & Total \\
\hline $\begin{array}{l}\text { No sport } \\
\text { Less sport } \\
\text { Same sport }\end{array}$ & E & $\begin{array}{l}\overline{4} \\
1\end{array}$ & $\begin{array}{r}1 \\
6 \\
14\end{array}$ & $\begin{array}{r}-4 \\
6\end{array}$ & $\begin{array}{l}2 \\
3 \\
7\end{array}$ & $\begin{array}{r}3 \\
17 \\
28\end{array}$ \\
\hline Total & - & 5 & 21 & 10 & 12 & 48 \\
\hline
\end{tabular}

Table 2. Subjective degree of 'giving way' after operation

\begin{tabular}{lrrrrrr}
\hline $\begin{array}{l}\text { Result } \\
\text { after } \\
\text { operation }\end{array}$ & Nil & $\begin{array}{c}\text { Felt } \\
\text { unstable }\end{array}$ & $\begin{array}{c}\text { Occasionally } \\
\text { at sport }\end{array}$ & $\begin{array}{c}\text { Regularly } \\
\text { at sport }\end{array}$ & $\begin{array}{c}\text { Any Total } \\
\text { time }\end{array}$ \\
\hline No sport & 1 & - & - & 2 & - & 3 \\
Less sport & 12 & 3 & 2 & - & - & 17 \\
Same sport & 18 & 7 & 3 & - & - & 28 \\
Total & 31 & 10 & 5 & 2 & - & 48 \\
\hline
\end{tabular}

Table 3. Preoperative Lachman displacement $(\mathrm{cm})$

\begin{tabular}{|c|c|c|c|c|c|c|c|c|}
\hline $\begin{array}{l}\text { Result after } \\
\text { operation }\end{array}$ & Nil & 0.25 & 0.5 & 0.75 & 1.0 & 1.25 & 1.5 & Total \\
\hline No sport & - & - & 1 & 1 & 1 & - & - & 3 \\
\hline Less sport & - & - & 5 & 11 & 1 & - & - & 17 \\
\hline Same sport & 1 & - & 5 & 19 & 2 & - & 1 & 28 \\
\hline Total & 1 & - & 11 & 31 & 4 & - & 1 & 48 \\
\hline
\end{tabular}

Table 4. Postoperative Lachman displacement $(\mathrm{cm})$

\begin{tabular}{|c|c|c|c|c|c|c|c|c|}
\hline $\begin{array}{l}\text { Result after } \\
\text { operation }\end{array}$ & Nil & 0.25 & 0.5 & 0.75 & 1.0 & 1.25 & 1.5 & Total \\
\hline No sport & - & - & 2 & - & 1 & - & - & 3 \\
\hline Less sport & 7 & - & 5 & 5 & - & - & - & 17 \\
\hline Same sport & 13 & - & 8 & 5 & 2 & - & - & 28 \\
\hline Total & 20 & - & 15 & 10 & 3 & - & - & 48 \\
\hline
\end{tabular}


Meniscal pathology noted at arthroscopy before a modified McIntosh procedure is recorded in Table 5, grouped as for outcome. In 38 patients, meniscal tears were treated as necessary at the time of repair. In the group returning to the same sport, 22 of 28 $(79 \%)$ had meniscal pathology, in the less sport group, 13 of $17(76 \%)$. In the group not returning to any sport, all three had meniscal tears. It would appear that meniscal damage treated at the time of a modified McIntosh repair does not affect outcome. It was also noted that postoperative pain was not related to meniscal surgery.

Postoperative pain was one of the reasons patients gave for not returning to sport and is shown in Table 6. Only 17 of 48 patients were rendered completely pain-free, although when the 14 with rare pain are added, 31 of $48(65 \%)$ accepted a description of 'comfortable'. Some pain was reported by all patients who did not participate in any sport, by 12 of 17 who participated in less sport and by 15 of 28 who returned to full sport.

Final analysis of the $28(58 \%)$ of patients returning to their normal level and type of sport showed a marked reduction in 'giving way'; 18 were fully stable. Lachman displacement was abolished in $50 \%$ and pain was present more than 'occasionally' in only two patients. Of the patients, $17(35 \%)$ were participating in different sports or lower levels of their previous sport. The reasons given were incapacitating instability in five knees, two were due to pain, and ten due to reasons unrelated to the knee. When asked, these patients thought that if so desired, they could perform at their previous level. Of the three doing no sport, two were due to instability and one due to social reasons.

If the 11 patients who voluntarily reduced their postoperative sporting expectations by not trying to regain a preoperative sporting level are excluded, the operation succeeded in giving a return to sport in 28 of 37 patients $(76 \%)$. Return to lesser sport occurred in 7 of $37(19 \%)$ patients and $2(5 \%)$ failed completely.

Table 5. Meniscal tears in patients with $\mathrm{ACL}$ rupture

\begin{tabular}{lrrrrr}
\hline $\begin{array}{l}\text { Result after } \\
\text { operation }\end{array}$ & Nil & Medial & Lateral & Both & Total \\
\hline No sport & - & 2 & - & 1 & 3 \\
Less sport & 4 & 9 & 1 & 3 & 17 \\
Same sport & 6 & 15 & 7 & - & 28 \\
Total & 10 & 26 & 8 & 4 & 48 \\
\hline
\end{tabular}

Table 6. Postoperative pain

\begin{tabular}{lrrrrrr}
\hline $\begin{array}{l}\text { Result } \\
\text { after } \\
\text { operation }\end{array}$ & None & Rare & Occasional & Frequent & Constant Total \\
\hline No sport & - & 1 & 1 & 1 & -1 & 3 \\
Less sport & 4 & 6 & 4 & 2 & 1 & 17 \\
Same sport & 13 & 7 & 6 & 2 & - & 28 \\
Total & 17 & 14 & 11 & 5 & 1 & 48 \\
\hline
\end{tabular}

Table 7. Sporting activities of patients returning to full capacity $(n=28)$

\begin{tabular}{lcccc}
\hline Sport & $\begin{array}{c}\text { Regular } \\
\text { club }\end{array}$ & County & National & Professional \\
\hline $\begin{array}{l}\text { Football } \\
\text { American football }\end{array}$ & 9 & 2 & & 1 \\
$\begin{array}{l}\text { Hockey } \\
\text { Netball }\end{array}$ & 2 & 1 & & \\
$\begin{array}{l}\text { Volleyball } \\
\text { Basketball }\end{array}$ & & 1 & & \\
$\begin{array}{l}\text { Squash } \\
\text { Badminton }\end{array}$ & 2 & 1 & & \\
Skydiving & 1 & 1 & & \\
Tennis & 1 & 1 & & \\
Martial arts & 1 & & 1 & 1 \\
Waterski & 1 & & & \\
Total & 17 & 9 & 1 & \\
\hline
\end{tabular}

Table 8. Sporting change in those not returning to full capacity $(n=17)$

\begin{tabular}{|c|c|}
\hline From & To \\
\hline $\begin{array}{l}\text { Semi-professional football } \\
\text { County football } \\
\text { Club football }(n=7)\end{array}$ & $\begin{array}{l}\text { Running, tennis } \\
\text { Club football } \\
\text { Lower team (2) } \\
\text { Running (2) } \\
\text { Cycling } \\
\text { Golf } \\
\text { Bowls }\end{array}$ \\
\hline $\begin{array}{l}\text { Club badminton } \\
\text { Club golf } \\
\text { Club rugby }(n=3)\end{array}$ & $\begin{array}{l}\text { Aerobics } \\
\text { Social golf } \\
\text { Social badminton } \\
\text { Social cricket } \\
\text { Social golf }\end{array}$ \\
\hline $\begin{array}{l}\text { National gymnastics } \\
\text { American Football Club } \\
\text { County trampoline }\end{array}$ & $\begin{array}{l}\text { Netball Club } \\
\text { Social squash } \\
\text { Social tennis }\end{array}$ \\
\hline
\end{tabular}

Table 7 lists the type and level of sport enjoyed by those returning to full activity and it can be seen that 11 patients returned to county level or higher performance. In the most popular sport, football, 12 patients resumed full capability. In the next group, Table 8, those returning to a lower level or different sport, 9 of 17 of these patients were footballers, only three carrying on the sport, but at a lower level. Three club rugby players changed to non-contact sports, as did most of the other sports persons. The national gymnast had a stable knee, but had outgrown the sport. Of the three who 'failed', two were club footballers, one of whom had persistent giving way, the other had pain secondary to degenerative change. The third was a club rugby player who retired voluntarily to preserve his knee in good order.

\section{Discussion}

This study illustrates the results of a modified McIntosh repair in terms of a practical end-point, i.e. a return to sporting ability. The modification of the McIntosh repair by suturing the iliotibial band back to its origin, rather than to itself, and to the lateral intermuscular septum, was intended to provide a more dynamic augmentation and lead to less 
stretching of the repair and hence loss of strength. At the time of review there had been no deterioration in the performance of any knee once a steady postrehabilitation state had been reached.

The $58 \%$ of patients who returned to full sport and the $35 \%$ returning to less sport after this procedure compare favourably with results of other series. Intra-articular patellar tendon reconstructions have produced variable results from a $30 \%$ return to full sports $^{1}$ to $83 \%$ returns to 'pre-injury' status ${ }^{8}$. Gracilis or semitendinosus tendon transfers have been reported as giving an approximately $50 \%$ return to 'sport' ${ }^{3,4}$. More recently, Holmes et al. ${ }^{9}$ confirm a $50 \%$ success rate for semitendinosus and $85 \%$ success rate for patellar tendon repairs on both subjective and objective cruciate testing. Return to sporting ability, however, was not quoted.

The original McIntosh repair has results similar to the Ellison repair, returning $80 \%$ of knees to good function, $14 \%$ fair and $6 \%$ poor, but return to pre-injury sports status has not been quoted, and there is evidence to suggest that these repairs weaken with time ${ }^{10}$. A 'good' result in this series consisted of a knee that could withstand sport with no more than 'occasional or recurring mild swelling or instability'.

The results of this operation suggest that it can return $58 \%$ of sportsmen to their original sport. The remainder who did not achieve this, did so either due to continued symptoms $(19 \%)$ or socioeconomic reasons $(23 \%)$. The latter group consisted of regular social sportsmen and women who altered their expectation of sporting level due to their injury and surgery to correct this, not wishing to compromise a satisfactory outcome by further trauma. Symptomatic giving way was abolished in $65 \%$ of cases as assessed by direct questioning of the patients, who it was felt were able to give an accurate account of their symptoms. Assessment of ligamentous laxity by the Lachman test was found to be readily reproducible between the operator (who examined all patients in clinic before operation) and the examiner. However, pivot shift was examined before operation under anaesthesia and the reproducibility of this test in the clinic is not reliable. Most patients, however, were able to describe not feeling 'that popping sensation' that they had when this test was attempted in outpatients before operation.
In summary, this retrospective analysis of 48 sportsmen and women shows a favourable outcome in terms of return to pre-injury sporting status, in comparison with other, more complex, technically demanding reconstructions. Of the patients, $56 \%$ returned to their previous level and type of sport; excluding those who did not try to attain this level for purely personal reasons, the 'success' rate rises to $76 \%$. On questioning the patients after operation $65 \%$ of knees were completely stable, and on examination Lachman displacement was reduced to $0.5 \mathrm{~cm}$ or less in $73 \%$ of patients. It remains to be seen how the patients perform after a longer follow-up.

\section{Acknowledgements}

Mr O. N. Tubbs, General Hospital, Birmingham, UK, for allowing the reporting of his patients.

\section{References}

1 Jones KG. Reconstruction of the anterior cruciate ligament. J Bone Joint Surg [Am] 1963; 45-A: 925.

2 O'Donoghue DH. A method for the replacement of the anterior cruciate ligament of the knee. J Bone Joint Surg [Am] 1963; 45-A: 905.

3 McMaster JH, Weinert CR. Diagnosis and management of anterior cruciate ligament tears and reconstruction with gracilis. J Trauma 1974; 14: 230-5.

4 Lipscomb AB, Johnstone RK. Reconstruction of the anterior cruciate ligament in athletes with semitendinosus. Am J Sports Med 1979; 7: 81-4.

5 Glausman R. Gore-Tex prosthetic ligament in anterior cruciate ligament deficient knees. Am J Sports Med 1988; 16: 321.

6 Durkan JA, Haggerty JF. Extra-articular reconstruction of the ACL insufficient knee. Ellison procedure. Am J Sports Med 1989; 17: 112.

7 McIntosh DL, Darby TL. Lateral substitution reconstruction. J Bone Joint Surg [Br] 1976; 58-B: 142.

8 Tibone JE, Antich TJ. A biomechanical analysis of the anterior cruciate ligament repair with the patellar tendon. Am J Sports Med 1988; 16: 332

9 Holmes PF, James SL, Larson RL, Singer KM, Jones DL. Retrospective direct comparison of three intra-articular anterior cruciate ligament reconstructions. Am J Sports Med 1991; 19: 596-9.

10 Ellison AE. Distal iliotibial band transfer for anterolateral rotatory instability of the knee. J Bone Joint Surg [Am] 1979; 61-A: 330-7. 